more energy than it consumes. ITER has been under construction since 2010 on a site next to the Cadarache nuclear-research facility north of Marseilles, France, but building costs have soared to roughly US $\$ 50$ billion - 10 times the original figure - and the schedule has slipped by 11 years. Instead of 2016, ITER is expected to start its first burning-plasma experiments in 2027- but only if the ITER team can solve technical challenges. ITER's plasma chamber follows the tokamak design that has dominated fusion-energy research since the 1970s. Multiple magnetic coils, fuel injectors and the like make tokamaks large and complex.

Even more problematic is the fusion fuel that ITER will ultimately use: a mix of the hydrogen isotopes deuterium and tritium. The mixture has the virtue of igniting at just 100 million kelvin, lower than other potential fuels, but it also produces most of its energy as neutrons, which will damage the reactor walls - and make the reactor radioactive, producing another nuclear-waste-disposal problem.

Given these realities, the prudent course for the world's funding agencies would be to support research into alternative fusion fuels, such as deuterium-helium-3 or proton-boron-11 - which require higher temperatures to ignite, but produce very few neutrons - as well as alternative reactor designs that would be simpler, cheaper and more in line with the kind of plant that power companies might buy (see page 398).

But that is not happening, because of ITER. The treaty that set up the project requires each of the seven ITER Organization members (the European Union, China, India, Japan, Korea, the Russian Federation and the United States) to contribute a fixed portion to the cost of construction - whatever that happens to be. Overruns have left fusion programmes with little cash for anything but ITER and the research efforts that support it.

The European Union, responsible for $45.5 \%$ of the cost, has been able to keep up by moving money from other projects. But the 9.1\% borne by the United States, which historically has been by far the most willing to fund alternative concepts, could not have come at a worse time for the nation. In 2009, as ITER's costs increased,

fusion-programme managers in the US Department of Energy were told by the administration of President Barack Obama that they would have to fulfil their share of ITER from a flat budget. In the ensuing crunch, nearly all the department's alternative fusion-research programmes have been cancelled.

Congress is furious. This year, the Senate voted to cancel the US contribution to ITER in fiscal year 2015, although the House of

"ITER promises to provide insights that will beinvaluable in any future power reactor." plan for fusion-energy research - something the agency has not had for many years.

Both of these activities provide openings for Congress and the energy department to restore some of the funding for alternative fusion research. Academic projects worthy of consideration include a radically simplified design for a fusion power reactor developed by Thomas Jarboe and his group at the University of Washington in Seattle: they believe that it could be built for about one-tenth of the cost of a tokamak. And among the small fusion start-up companies worth considering for a federal small-business grant is Lawrenceville Plasma Physics in Middlesex, New Jersey, which is trying to exploit a configuration known as a dense plasma focus to build an extremely compact reactor that does not emit neutrons.

And ITER? For all its problems, ITER promises to provide scientists with key insight into the physics of burning plasmas - insight that will be invaluable in any future power reactor, whatever its design. On balance, assuming no more major delays or cost surprises, the United States and the other partners should continue their support for ITER - but they must not allow it to drive fusion energy into a dead end.

\section{A fate sealed}

\section{Exploring how species adapt to climate change requires long-term studies, not snapshots.}

A s the world warms, fish can swim north and butterflies can head to higher ground, but what is a 2-metre-long, 200-kilogram Antarctic fur seal stranded on a remote island to do? More to the point, what are several million of them to do?

The common refrain for species facing climate change is that they must migrate or adapt - or perish. Some, such as trees, will find it difficult to move their ranges quickly enough. And others, including polar bears, already live at the limit of their habitable range, so have nowhere to go.

Adaptation is nature's best response to a crisis: after all, evolution and natural selection have been turning niche problems into opportunities for billions of years. It is no coincidence that people who are opposed to action on curbing carbon emissions talk up humanity's ability to adapt as if it were a deliberate choice of action; some species just make it look so easy.

But adaptation is not as simple as it looks, especially if future generations are to benefit from the changes. As a special issue of the journal Evolutionary Applications made clear in January (see go.nature. $\mathrm{com} / 8$ pruey), researchers too often infer that a species is responding to threats such as global warming through genetic evolution, just because the change seems to be the right thing for that species to do in the circumstances. Of course it would seem intuitive that a particular sea

bird has evolved to be smaller with climate change: a warmer world saps less of the bird's internal warmth, so it can be lighter - right?

Not always. As a study on page 462 of this issue makes clear, the situation is often more involved than that. Back to the Antarctic fur seals (Arctocephalus gazella) on that remote island, the polar outpost of South Georgia. On the front line of exposure to rising temperatures and with little scope for migration, the fur seals seem a prime example of a species that must adapt to survive, and quickly. Sure enough, as a genetic analysis of the population over the past few decades indicates, breeding female seals have become more heterozygous - a standard measure of Darwinian fitness and of an individual's resilience in the face of environmental adversity.

Again, this simple narrative is intuitive: of course the seals would respond to stressful conditions with greater genetic capacity to deal with them.

Why, then, has the study found that the fur-seal population is shrinking? Heterozygosity is valuable, but not heritable. The average heterozygosity of the seal pups being born has not changed. But the number of less-heterozygous pups that survive to breed has declined - the less fit are being weeded out as expected. The survivors are older when they breed and do so less often than in previous decades, which contributes to the observed $25 \%$ reduction in the population.

What is driving this effect? Climate change, or its proxy of locally changed weather patterns, seems to have an indirect role. Models suggest that weather changes reduce the availability of the seal's

$\rightarrow$ NATURE.COM To comment online, click on Editorials at: go.nature.com/xhunqv preferred food, Antarctic krill. So too, however, could altered fishing practices and the recovery of whale numbers.

What is a seal to do? The answer is more complicated than it seems. But so is the question. 